Case Report

\title{
A Case of Pheochromocytoma Revealed by an Etonogestrel Contraceptive Implant Use
}

\author{
Sitraka Angelo Raharinavalona*, Nathan Ratsimarisolo, Rija Eric Raherison, \\ Solofo Andrianarivelo Ralamboson, Hanta Marie Danielle Vololontiana, \\ Andrinirina Dave Patrick Rakotomalala
}

Faculty of Medicine, University of Antananarivo, Antananarivo, Madagascar

Email address:

sitrakarah $a$ gmail.com (S. A. Raharinavalona)

${ }^{*}$ Corresponding author

\section{To cite this article:}

Sitraka Angelo Raharinavalona, Nathan Ratsimarisolo, Rija Eric Raherison, Solofo Andrianarivelo Ralamboson, Hanta Marie Danielle Vololontiana, Andrinirina Dave Patrick Rakotomalala. A Case of Pheochromocytoma Revealed by an Etonogestrel Contraceptive Implant Use. International Journal of Diabetes and Endocrinology. Vol. 6, No. 1, 2021, pp. 5-8. doi: 10.11648/j.ijde.20210601.12

Received: December 13, 2020; Accepted: December 21, 2020; Published: January 12, 2021

\begin{abstract}
Background: Pheochromocytoma (PH) is a rare tumor developed at the expense of the adrenal medulla and secreting catecholamines. It is also a rare cause of curable hypertension in adults. Case information: We reported a case of PH in a 39-year-old Malagasy woman, with no particular history. The clinic was dominated by the onset of paroxysmal hypertension associated with headache, palpitations, and sweating. Its clinical manifestations were revealed by the insertion of an etonogestrel contraceptive implant. Despite the removal of the contraceptive implant and the taking of an antihypertensive drug based on a calcium channel blocker, the hypertension persisted with a paroxysmal character and always associated with the Menard triad. Results: The diagnosis was made against the elevation of urinary metanephrines and normetanephrines and the presence of a heterogeneous left adrenal mass on computed tomography. Surgical resection of the tumor made it possible to perform an immunohistochemical examination confirming the diagnosis. Without surgical complications, the patient's blood pressure as well as urinary metanephrine and normetanephrine, normalized without taking any antihypertensive drug. Conclusion: Hormonal contraception could be wrongly blamed the cause of hypertension. Then she would just be a triggering factor. Thus, any atypical hypertension following the use of a hormonal contraceptive must encourage the search for a secondary cause such as $\mathrm{PH}$.
\end{abstract}

Keywords: Contraceptive Implant, Metanephrines, Normetanephrine, Pheochromocytoma

\section{Introduction}

Pheochromocytoma $(\mathrm{PH})$ is a rare endocrine tumor, developed at the expense of chromaffin cells of the adrenal medulla and producing catecholamine [1]. It is a rare cause of curable hypertension with a prevalence associated with paraganglioma, of the order of $0.2 \%$ to $0.6 \%$ [2]. $\mathrm{PH}$ is probably underdiagnosed because it represents $3 \%$ to $7 \%$ of incidentally discovered adrenal tumor $[3,4]$. However, in the absence of adequate management, cardiovascular morbidity and mortality remain high in $\mathrm{PH}[5,6]$. In Africa as in Madagascar, very few studies have devoted themselves to this subject. Thus we report a case of $\mathrm{PH}$ revealed by an etonogestrel contraceptive implant use, seen in the endocrinology department of the University Hospital Center Joseph Raseta Befelatanana, Antananarivo.

\section{Case Presentation}

It was a 39-year-old Malagasy woman, who had two pregnancies with two living children and no other specific history. His illness began in 2016 with the discovery of hypertension at 180/100 mmHg, without accompanying signs, following a strong emotion. She was treated by Amlodipine $10 \mathrm{mg}$ daily. After 2 weeks, blood pressure normalized $(111 / 72 \mathrm{mmHg})$, prompting him to stop his treatment at his own discretion. Since the insertion of an etonogestrel contraceptive implant in 2018, paroxysmal hypertension at $180 / 110 \mathrm{mmHg}$ reappeared, this time 
accompanied by headache, palpitations, and profuse sweating. Despite the resumption of its previous treatment and the withdrawal of the contraceptive implant, the hypertension in paroxysm persisted. She had thus consulted in our department, in 2019. At physical examination, blood pressure was $153 / 94 \mathrm{mmHg}$, pulse was 113 beats $/$ min, body mass index was $18.8 \mathrm{~kg} / \mathrm{m}^{2}$. The rest was unremarkable.

Standard biological examinations (kidney function, hemogram, ionograms, lipid profile and fasting plasma glucose) were normal. Urinary normetanephrine and
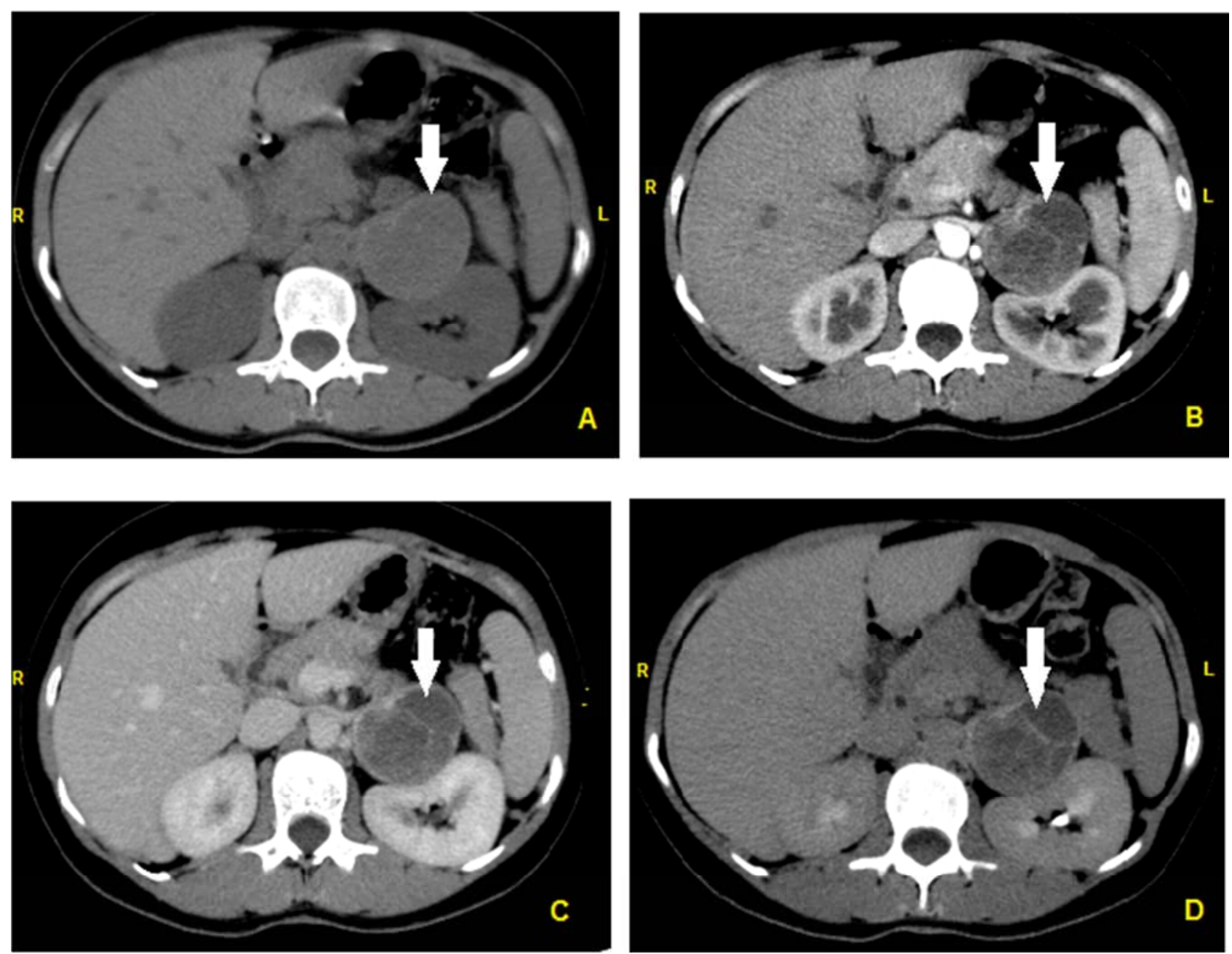

Figure 1. Abdominal-pelvic computed tomography showing a heterogeneous mass at the expense of the left adrenal gland including the calculation of the relative wash-out (15\%) in favor of a pheochromocytoma (In the axial plane, A: non-enhanced CT; B: contrast-enhanced CT arterial phase; C: contrast-enhanced CT venous phase and D: contrast-enhanced CT delayed phase 10 min after).
The patient underwent a partial left adrenalectomy potting the mass, without any immediate complications. The microscopic anatomopathological examination of the mass revealed, within the adrenal parenchyma, a tumor proliferation made of large or even giant pleomorphic cells, often nucleated, with finely granular cytoplasm, with moderate cytonuclear atypies, of diffuse architecture, by places in spans or nests, richly vascularized and limited at the metanephrine were raised to $10.69 \mu \mathrm{mol} / 24 \mathrm{~h}$ (reference range: $0.40-2.10$ ) and $4.49 \mu \mathrm{mol} / 24 \mathrm{~h}$ (reference range: $0.20-1.00$ ), respectively. After having complied with the conditions of sampling, the other hormonal assessments (aldosterone-renin ratio and 24-h urinary free cortisol) showed no abnormality.

Abdominal-pelvic computed tomography (CT) had objectified a heterogeneous mass (size: $4.67 \times 4.23 \times 3.75 \mathrm{~cm}$ ) at the expense of the left adrenal with relative Wash-out calculation 15\% (Figure 1). periphery by fibrous condensation. On immunohistochemical examination, tumor proliferation strongly expresses chromogranin and synaptophysin, compatible with a $\mathrm{PH}$.

Clinical course was favorable with normalization of blood pressure after 3 weeks without drug treatment. Urinary normetanephrine and metanephrine also normalized 12 months after adrenalectomy (Figure 2). 


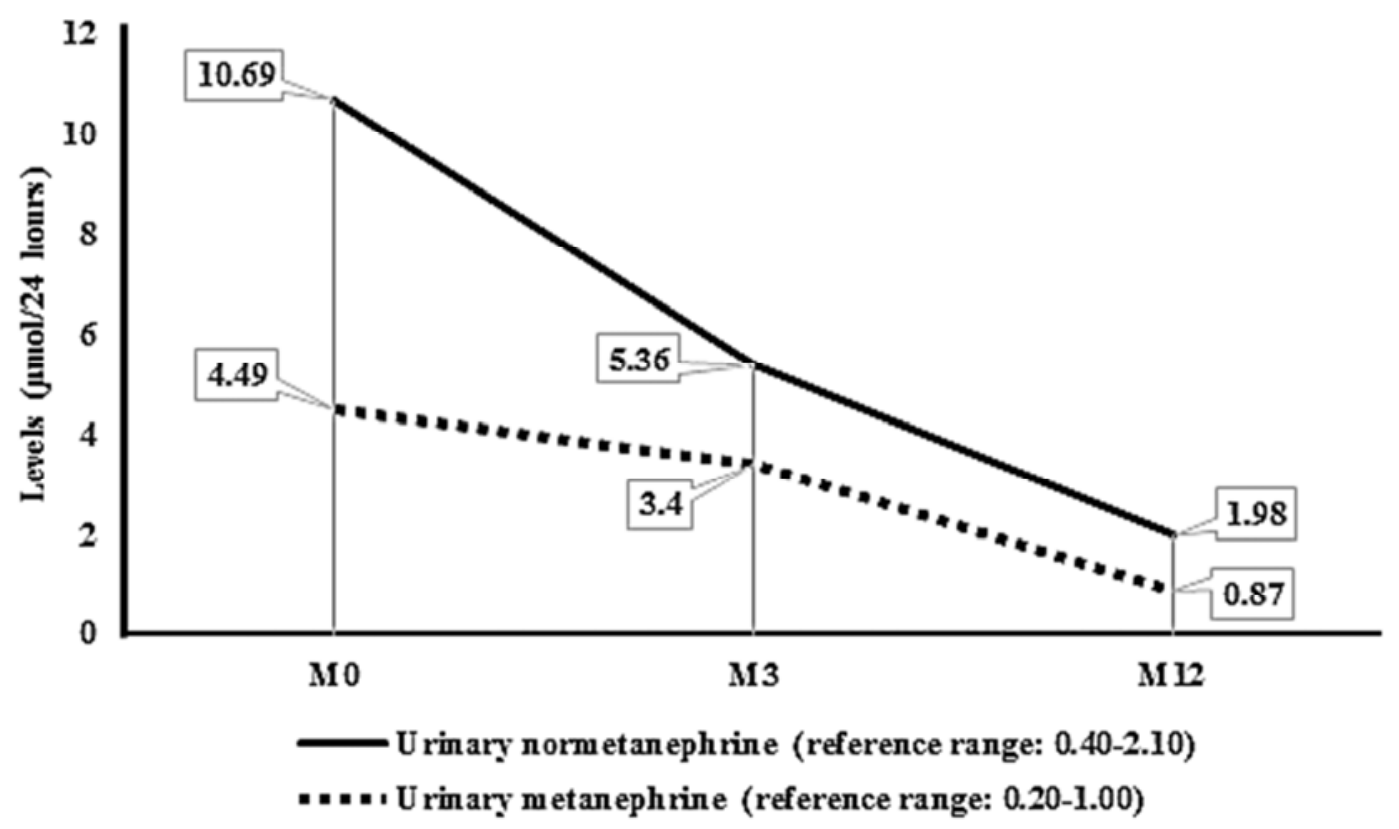

Figure 2. Kinetics of urinary normetanephrine and metanephrine. M0: before surgery; M3: 3 months after surgery; M12: 12 months after surgery.

\section{Discussion}

The clinical presentation of $\mathrm{PH}$ is very heterogeneous. It is dominated by the classic triad (headache, palpitations and sweating) associated with paroxysmal hypertension in $50 \%$ of cases or permanent in $40 \%$ of cases. Normal blood pressure is seen only in 5 to $15 \%$ of cases. The presence of this triad has a sensitivity of $89 \%$ and specificity of $67 \%$, and of hypertension of $91 \%$ and $94 \%$, respectively [7, 8]. Patients can also present other symptoms (orthostatic hypotension, visual disturbances, pallor, weight loss, polyuria, polydipsia, anxiety, tremor, abdominal or chest pain, nausea, vomiting, diarrhea or constipation, chart of heart failure) $[9,10]$.

In our case, the patient presented with paroxysmal hypertension associated with the classic triad, revealed by an etonogestrel contraceptive implant use. Indeed, a high concentration of exogenous estrogens cause rapid release of dopamine, via the cyclic adenosine monophosphate/Protein kinase A pathway and N-type calcium channels, in $\mathrm{PH}$ cells $[11,12]$. In addition, the estrogen of hormonal contraceptives activates the Renin-Angiotensin-Aldosterone System, causing a significant increase in blood pressure. Hypertension affected $2.8 \%$ of women on this contraceptive with an increase of 8 and $6 \mathrm{mmHg}$ for systolic and diastolic pressure, respectively $[13,14]$.

The dosages of catecholamine metabolites (metanephrines, normetanephrines) in plasma or urine for 24 hours allow the diagnosis of $\mathrm{PH}$ to be made. This urine assay that we used for our patient already has excellent sensitivity (97\%) and specificity (91\%) [15]. Furthermore, the combination of methanephrine and dopamine metabolite 3-methoxytyramine plasma assays offers slightly more sensitivity (99\%) [2].

For the topographic diagnosis, abdominal-pelvic CT nonand contrast-enhanced is the most commonly used imaging test. It allows visualizing tumors larger than $0.5-1 \mathrm{~cm}$ and has the advantage of a low cost. Its sensitivity is high, estimated to be greater than $95 \%[16,17]$. Magnetic resonance imaging is only to be asked in some situations (children, pregnant women, proven allergy to $\mathrm{CT}$ contrast). Functional imaging such as ${ }^{123}$ I-metaiodobenzylguanidine (MIBG) scintigraphy and positron emission tomography coupled with $\mathrm{CT}$ scanning (PET/CT), makes it possible to locate a tumor not seen in previous imaging and to search for multi-focal or metastatic disease $[2,18]$.

Once the diagnosis of $\mathrm{PH}$ is made, the cornerstone of treatment remains surgical resection. It must be preceded by medical treatment based on the combination of alpha- and beta-blockers in order to control blood pressure before and after surgery. The use of calcium channel blockers has also been proven in the literature [3].

After adrenalectomy, the rate of recurrence of $\mathrm{PH}$ varied between 6 to $23 \%$. And the size of a tumor greater than $5 \mathrm{~cm}$ was identified as a predictor of this recurrence $[19,20]$. Consequently, patients must benefit from clinical (adrenergic signs, blood pressure) and biochemical (metanephrines, normetanephrines) follow-up once a year in the case of unilateral PH less than $5 \mathrm{~cm}$ in diameter, and at 6 months then annually in the event of $\mathrm{PH}$ more than $5 \mathrm{~cm}$ in diameter, family history of $\mathrm{PH}$ or paraganglioma [18, 21]. In the event of a further elevation of these biochemical markers, metastases should be sought by MIBG scintigraphy and the $\mathrm{PET} / \mathrm{CT}[22]$.

\section{Conclusion}

Pheochromocytoma is a rare cause of curable hypertension that can be mistaken for the side effect of a hormonal contraceptive, like an etonogestrel contraceptive implant. The paroxysmal character of hypertension associated with the 
classic triad must evoke its diagnosis. Biochemical and radiological explorations allow the diagnosis of the tumor to be made. The main treatment consists of surgical resection followed by clinical and biological follow-up. Therefore, any atypical hypertension following a hormonal contraceptive use must be the subject of research for a secondary cause such as pheochromocytoma.

\section{Statement of Ethics}

The patient has given his informed consent.

\section{Competing Interests}

The authors declare that they have no competing interests.

\section{References}

[1] Neumann H. Pheochromocytoma. In: Kasper DL, Hauser SL, Jameson JL, Fauci AS, Longo DL, Loscalzo J, editors. Harrison's principles of internal medicine. 19th Edition. New York: McGraw-Hill; 2015. p. 2329-35.

[2] Lenders JWM, Eisenhofer G. Update on Modern Management of Pheochromocytoma and Paraganglioma. Endocrinol Metab 2017; 32: 152-61.

[3] Neumann H, Young WF, Eng C. Pheochromocytoma and Paraganglioma. N Engl J Med 2019; 381: 552-65.

[4] Cawood TJ, Hunt PJ, O'Shea D, Cole D, Soule S. Recommended evaluation of adrenal incidentalomas is costly, has high false-positive rates and confers a risk of fatal cancer that is similar to the risk of the adrenal lesion becoming malignant: time for a rethink? Eur J Endocrinol 2009; 161: 513-27.

[5] Riester A, Weismann D, Quinkler M, Lichtenauer UD, Sommerey S, Halbritter R, et al. Life-threatening events in patients with pheochromocytoma. Eur J Endocrinol 2015; 173: 757-64.

[6] Zelinka T, Petrák O, Turková H, Holaj R, Štrauch B, Kršek M et al. High incidence of cardiovascular complications in pheochromocytoma. Horm Metab Res. 2012; 44: 379-84.

[7] Sánchez-Turcios RA. Pheochromocytomas: diagnosis and treatment. Rev Mex Cardiol 2015; 26 (3): 118-24.

[8] Farrugia FA, Martikos G, Tzanetis P, Charalampopoulos A, Misiakos E, Zavras N et al. Pheochromocytoma, diagnosis and treatment: Review of the literature. Endocrine Regulations 2017; 51 (3): 168-81.

[9] Thompson LDR. Pheochromocytoma. Pathology Case Reviews 2005; 10: 243-51.

[10] Cai Q, Xu Z, Yang N, Shao D, Zhang R, Li H et al. A case of pheochromocytoma presenting with Takotsubo cardiomyopathy as the frst symptom without hypertension. Int J Clin Exp Med 2019; 12 (5): 6447-51.

[11] Alyea RA, Laurence SE, Kim SH, Katzenellenbogen BS, Katzenellenbogen JA, Watson CS. The roles of membrane estrogen receptor subtypes in modulating dopamine transporters in PC-12 cells. J Neurochem. 2008; 106 (4): 1525 1533.

[12] Alyea RA, Watson CS. Differential Regulation of Dopamine Transporter Function and Location by Low Concentrations of Environmental Estrogens and 17 $\beta$-Estradiol. Environ Health Perspect 2009; 117: 778-783.

[13] Haroon S, Naveed KA. Effect of hormonal contraceptives on serum electrolytes and blood pressure. J Post Med Inst 2014; 28 (4): 409-13.

[14] Ribeiro CCM, Shimo AKK, Lopes MHBM, Lamas JLT. Effects of different hormonal contraceptives in women's blood pressure values. Rev Bras Enferm [Internet]. 2018; 71 (Suppl 3): 1453-9.

[15] Perry CG, Sawka AM, Singh R, Thabane L, Bajnarek J, Young Jr WF. The diagnostic efficacy of urinary fractionated metanephrines measured by tandem mass spectrometry in detection of pheochromocytoma. Clin Endocrinol (Oxf). 2007; 66: 703-708.

[16] Čtvrtlík F, Koranda P, Schovánek J, Škarda J, Hartmann I, Tüdös Z. Current diagnostic imaging of pheochromocytomas and implications for therapeutic strategy (Review). Exp Ther Med 2018; 15: 3151-60.

[17] Baez JC, Jagannathan JP, Krajewski K, O'Regan K, Zukotynski K, Kulke $M$ et al. Pheochromocytoma and paraganglioma: imaging characteristics. Cancer Imaging 2012; 12: 153-162.

[18] Lenders JW, Duh QY, Eisenhofer G, Gimenez-Roqueplo AP, Grebe SK, Murad MH, et al. Pheochromocytoma and paraganglioma: an endocrine society clinical practice guideline. J Clin Endocrinol Metab 2014; 99: 1915-42.

[19] Johnston PC, Mullan KR, Atkinson AB, Eatock FC, Wallace H, Gray $M$ et al. Recurrence of phaeochromocytoma and abdominal paraganglioma after initial surgical intervention. Ulster Med J 2015; 84 (2): 102-106.

[20] Press D, Akyuz M, Dural C, Aliyev S, Monteiro R, Mino J et al. Predictors of recurrence in pheochromocytoma. Surgery 2014; 156: $1523-8$.

[21] Amar L, Fassnacht M, Gimenez-Roqueplo A-P, Januszewicz A Prejbisz A, Timmers $\mathrm{H}$ et al. Long-term Postoperative Follow-up in Patients with Apparently Benign Pheochromocytoma and Paraganglioma. Horm Metab Res 2012; 44: 385-389.

[22] Taïeb D, Hicks RJ, Hindié E, Guillet BA, Avram A, Ghedini P et al. European Association of Nuclear Medicine Practice Guideline/Society of Nuclear Medicine and Molecular Imaging Procedure Standard 2019 for radionuclide imaging of phaeochromocytoma and paraganglioma. Eur J Nucl Med Mol Imaging 2019; 46 (10): 2112-2137. 